\title{
Number of Episodes
}

National Cancer Institute

\section{Source}

National Cancer Institute. Number of Episodes. NCI Thesaurus. Code C124281.

A measurement of the total number of events that have occurred. 